\title{
Ventricular pacing improves exercise tolerance in patients with chronic heart block
}

\author{
M PAPOUCHADO, D W PITCHER* \\ From the Department of Cardiology, Bristol Royal Infirmary
}

SUMMARY Exercise capacity was assessed by means of a simple six minute walking test in a group of 18 patients with heart block whose only presenting symptom was breathlessness. None was in overt cardiac failure. Patients were studied before and after implantation of a transvenous, ventricular, demand pacing system (study group). Eight patients with an implanted pacemaker admitted for elective generator replacement were assessed in the same manner (control group). Exercise capacity in the study group was significantly increased within 48 hours of pacing, and this improvement was maintained in most patients during the follow up period of up to 30 months. In contrast, exercise capacity was unaffected by generator replacement in the control group.

Simple ventricular pacing produces symptomatic benefit in patients with heart block accompanied by breathlessness. This benefit is apparent within 48 hours of pacing and is maintained; it can be assessed objectively by a six minute walking test.

Indications for implantation of permanent pacing systems in patients with heart block have been termed "hard" (syncope) and "soft" (cerebral dysfunction and cardiac failure). In Britain few pacemakers are implanted for "soft" indications, although recent guidelines from the pacing subcommittee of the joint American College of Cardiology/ American Heart Association task force on assessment of cardiovascular procedures include "marked exercise intolerance" as "symptomatic bradycardia" and hence an indication for permanent pacing. ${ }^{2}$ While some patients with heart block and syncope note that their exercise tolerance improves after pacing ${ }^{3}$ many patients with heart block whose sole complaints are breathlessness or cardiac failure still remain unpaced. ${ }^{4}$ Several studies have shown an improvement in cardiovascular haemodynamic function with pacing at different rates, ${ }^{5-7}$ but none has related these findings to changes in symptoms. One study concluded that in the absence of syncope pacing was of little symptomatic benefit, but this

Requests for reprints to $\operatorname{Dr} M$ Papouchado, Department of Cardiology, Bristol Royal Infirmary, Bristol, Avon BS2 8HW.

*Present address, County Hospital, Hereford.

Accepted for publication 23 June 1986 was partly based on retrospective review of clinical and radiological data in a group of patients with congestive cardiac failure. ${ }^{3}$

We have used a simple six minute walking test ${ }^{89}$ to assess the effect of ventricular pacing on exercise capacity in a group of patients with heart block whose only presenting symptom was breathlessness.

\section{Patients and methods}

Patients with heart block referred to the cardiology department at the Bristol Royal Infirmary from 1 August 1983 to 31 November 1984 were considered for inclusion in the study. All were assessed by history, clinical examination, 12 lead electrocardiogram, and chest radiograph. Patients with regular bradycardia caused by heart block (complete or 2:1) and who suffered from breathlessness without syncope or dizziness were asked to participate. Those with atrial fibrillation and a slow ventricular response, important valvar heart disease, recent myocardial infarction (within three months), overt heart failure (six patients), or heart block after cardiac operation were excluded. Five patients with additional chronic airways disease were included. None had anaemia or hypothyroidism. Drugs likely to interfere with atrioventricular conduction had 
Ventricular pacing improves exercise tolerance in patients with chronic heart block

tble 1 Details of patients recruited for the study and results of 6 minute walks

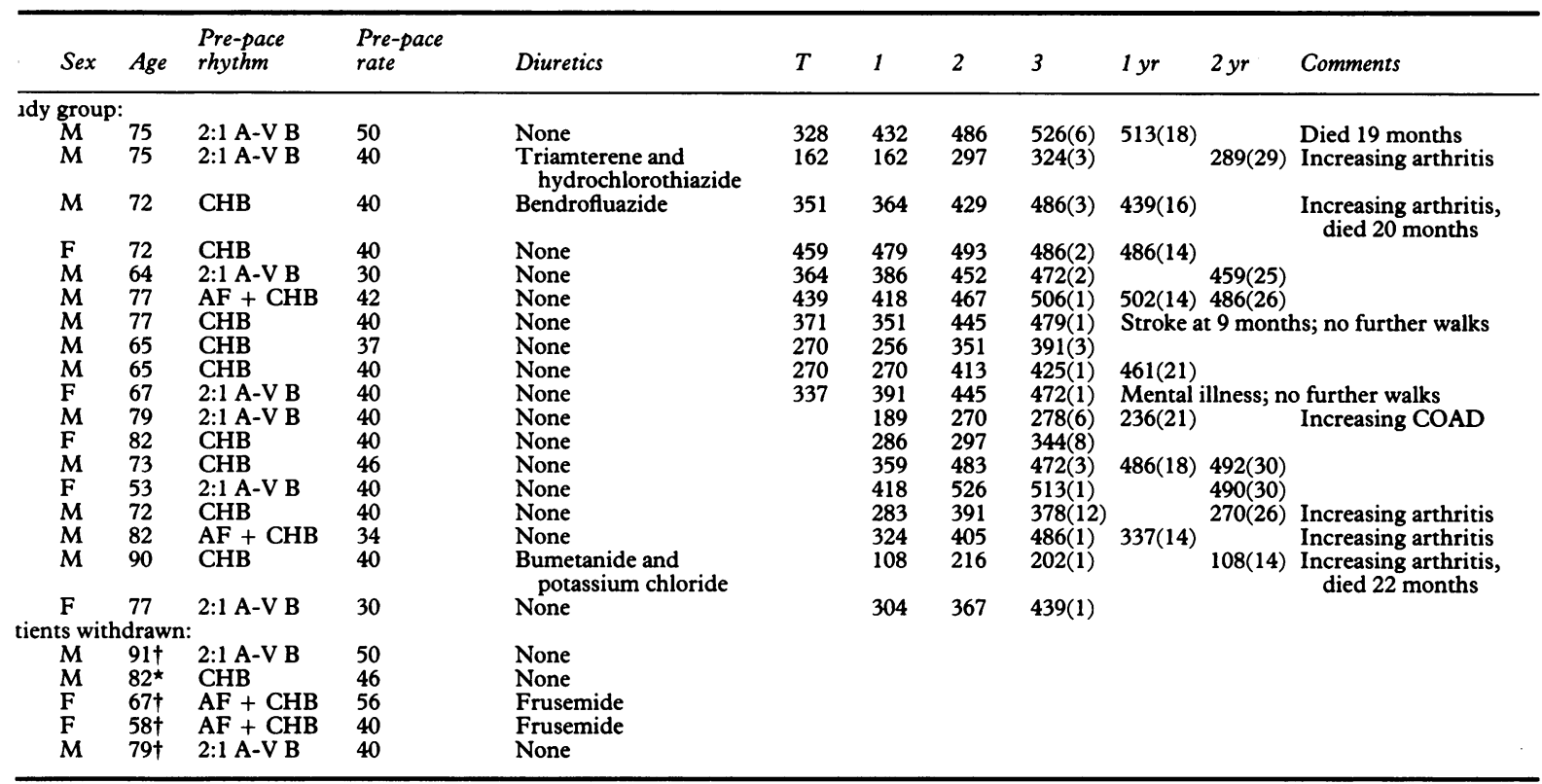

A-V B, 2:1 atrioventricular block; CHB, complete heart block; AF, atrial fibrillation; COAD, chronic obstructive airways disease. tients $2,8,11,19$, and 21 had chronic airways obstruction. Patient 9 had mild aortic valve regurgitation.

'atient died before re-study.

egained intermittent $\mathrm{A}-\mathrm{V}$ conduction post-pacing.

"training" walk; 1, Immediately before pacing; 2 , short term walk at 48 h; 3 , long term walk between 1 and 12 months; 1 yr, walk between 13 and 24

snths; 2 yr, walk between 25 and 36 months. Walks in metres covered in 6 min. Figure in parentheses indicate months since pacing.

been stopped at least two weeks before pacing but other treatment remained unchanged.

During the study period 268 patients ( 145 male, 123 female) received a new, permanent pacing system; 172 were judged to be in chronic heart block, while 94 had evidence of intermittent atrioventricular block or sinoatrial disease; two patients had recurrent ventricular tachycardia. Twenty three $(13 \%)$ patients with "chronic" heart block fulfilled the criteria and were included in the study (table 1). Eighteen patients completed the study and are the subject of this report; five patients were subsequently withdrawn from the study after pacing. All patients were paced by the transvenous route by standard techniques and VVI generators set at 70 beats per minute. Eight patients admitted for elective replacement of a previously implanted pacemaker were used as controls (table 2).

Exercise capacity was assessed by a simple six minute walking test ${ }^{89}$ along a hospital corridor (length 27 metres). Subjects were asked to walk as far as they could in six minutes, continuously if possible, but to slow down or to stop for short rests during the test if necessary. The total distance walked was noted as were any stops or symptoms.
To assess any training effect, subjects were exercised twice (if possible) before their procedures (new pacing system or generator change). Subsequent walking tests were performed at $\mathbf{4 8}$ hours (the short term test), and again between one and twelve months later (the long term test) when patients returned for their pacing check. In some patients the walking test has been repeated after the one year period (table 1). Each patient was supervised by the same investigator for all of their walking tests.

Results are expressed as mean (1 SD). Student's paired $t$ test was used; statistical significance was taken as $\mathrm{p}<0.05$.

Table 2 Details of control patients

\begin{tabular}{llll}
\hline No & Sex & Age & Years paced \\
\hline 24 & M & 66 & 4 \\
25 & M & 61 & 6 \\
26 & M & 73 & 12 \\
27 & M & 77 & 4 \\
28 & F & 78 & 5 \\
29 & F & 75 & 5 \\
30 & M & 80 & 5 \\
31 & M & 79 & 4 \\
\hline
\end{tabular}



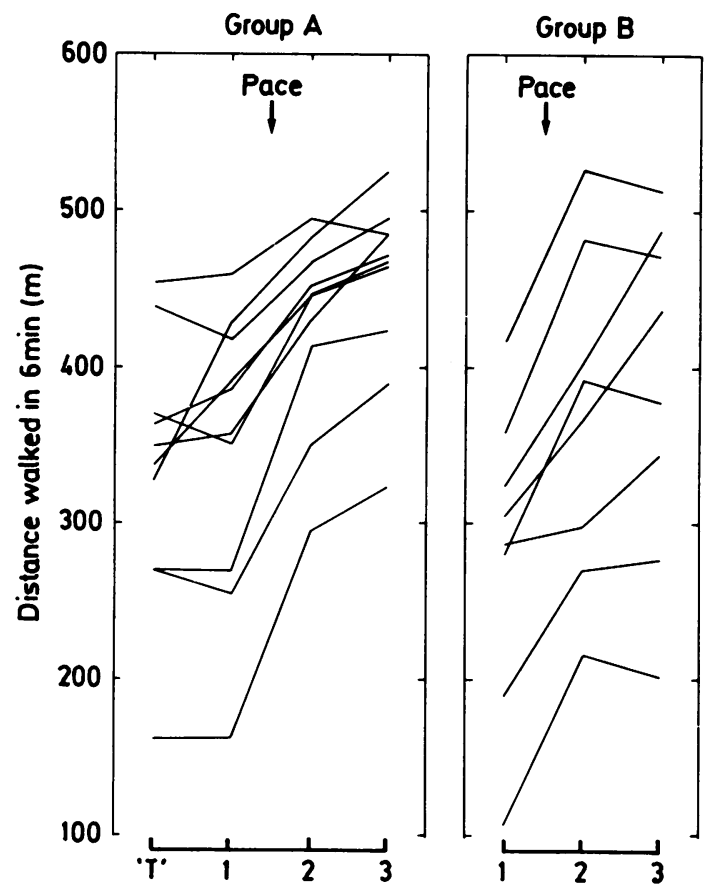

Fig 1 Results of a 6 minute walking test in 10 patients who had two walking tests before pacing (group $A$ ) and in eight patients who had one walking test before pacing (group $B$ ). $T$, "Training" walk; (1), immediately before pacing; (2), $48 \mathrm{~h}$ after pacing; (3), 1-12 months after pacing. Group $A$ : T vs $1,334.8$ (83.7) vs 348.3 (84.5), NS. Group $A+B: 1$ vs $2,318.6$ (99.9) vs $399.6(86.4), p<0.001 ; 2$ vs 3 , $399.6(86.4)$ vs $423.9(89.1), p<0.05$. All distances are in metres $\pm 1 S D$.

\section{Results}

\section{EXERCISE CAPACITY}

Group A consisted of 10 patients (eight male, two female; age 64-78, mean (SD) 70.9 (5.2) years) who had two walking tests before pacing. There was no significant difference between the distances walked during these two tests $(334.8(83 \cdot 7)$ vs $348.3(84 \cdot 5)$ $\mathrm{m}$ ), and hence no significant training effect (fig 1 ).

Group B consisted of eight patients (six male, two female, age 53-90, mean (SD) $76.0(10.9)$ years) in whom it was only possible to perform one walking test before pacing (fig 1). There was no significant age or sex difference between groups $A$ and $B$, which may be regarded as subgroups of the same population, and for further analysis we considered them as one group of 18 patients ( 13 male, five female, age 53-90, mean $73 \cdot 1(8 \cdot 3)$ years).

In these 18 patients the distance walked increased from $318.6(99.9)$ metres before pacing to 399.6

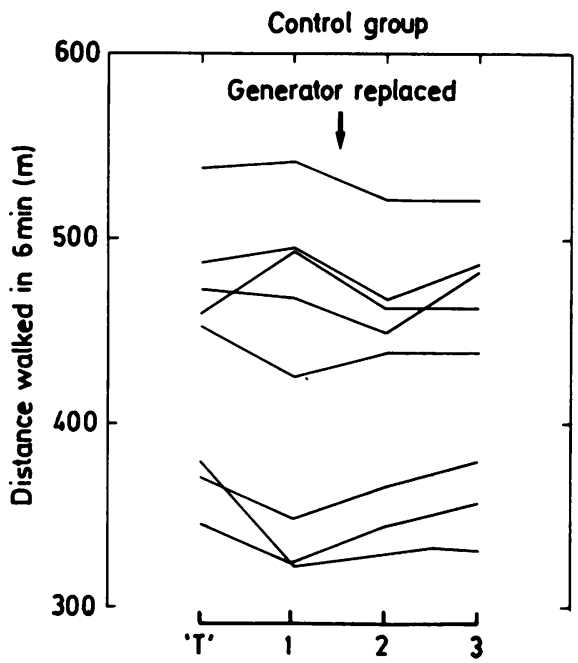

Fig 2 Results of 6 minute walks in eight control patients. $T$, "Training" walk; (1), immediately before pacing; (2), $48 \mathrm{~h}$ after pacing; (3), 1-12 months after pacing. Control group: $T$ vs $1,437.4(66.1)$ vs 426.6 (83.7), NS; 1 vs 2 , $426.6(83.7)$ vs $429.3(72 \cdot 9), N S ; 2$ vs $3,429.3(72 \cdot 9)$ vs $432(67 \cdot 5), N S$.

All distances are in metres $\pm 1 S D$.

(86.4) $\mathrm{m}$ after pacing ( $p<0.001)$. There was a further improvement in exercise capacity during the long term test (399.6 (86.4) vs $423.9(89.1) \mathrm{m}, \mathrm{p}<$ $0.05)$. This test occurred at one month in eight patients, two months in two patients, three months in four patients, six months in two patients, eight months in one patient, and 12 months in one patient.

There was no significant age or sex difference between the study and control groups. No training effect was seen in the control group (fig 2); there was no significant difference in exercise capacity between the two walks before generator change $(437.4(66 \cdot 1)$ vs $426.6(83.7) \mathrm{m}$ ) and distances walked immediately before and after generator change were similar (426.6 (83.7) vs $429.3(72.9) \mathrm{m})$. Exercise capacity remained unaltered on subsequent testing (429.3 (72.9) vs $432.0(67.5) \mathrm{m}$ ).

\section{SYMPTOMS}

Ten of the 18 patients in the study group had to stop at least once and seven at least twice during their pre-pacing walks because of breathlessness or fatigue. Fifteen of the 18 patients felt breathless or exhausted at the end of their pre-pacing walks. In contrast, none of the patients needed to stop because of breathlessness or fatigue during their post-pacing walks and all felt less breathless at the end. The three patients with chronic airways disease who completed the study (cases 2,8 , and 11 ) showed an 
improvement in their exercise capacity after pacing.

None of the patients in the control group needed to stop because of breathlessness during any of their walking tests, and exercise capacity was unaltered after replacement of their pacemaker generators.

\section{FOLLOW UP}

The 18 patients in the study group have been followed up regularly in the pacing clinic and 13 have been re-exercised, in some cases more than once, at least one year after being paced (table 1). Three patients (cases 1, 3, and 17) have died suddenly and a fourth (case 7) has had a left hemiparesis since entering the study. Patient 10 became mentally disturbed and has required admission to hospital so that it was not possible to repeat her walking test. The other patients in the study group remain in good health and have felt much better since being paced. The improvement in exercise capacity, as judged by walking distance, has been maintained in most of them, in some cases for up to 30 months after pacing. Exercise capacity was limited by arthritis in five patients and chronic airways disease in one, but nevertheless in four of these six patients it was better after pacing.

\section{Discussion}

The association between bradycardia and syncope had been noted by at least four observers, Marcus Gerbezius (or Verbez) of Laibach in $1719^{10}$ Giovanni Morgagni in $1769,{ }^{11}$ Thomas Spens in $1793,{ }^{12}$ and Sir William Burnett in $1824,{ }^{13}$ before the publications of Robert Adams in $1827^{14}$ and William Stokes in $1846 .{ }^{15}$ The patients described by Morgagni ${ }^{11}$ and Burnett ${ }^{13}$ both suffered, in addition, from paroxysmal nocturnal dysnoea and Robert Adams's ${ }^{14}$ patient had both syncope and cardiac failure.

Syncopal episodes, however, have tended to overshadow breathlessness as a typical symptom of heart block because of their dramatic nature and the abolition of symptoms by pacing. ${ }^{3}$ Nevertheless, some patients with heart block present with breathlessness or cardiac failure in the absence of syncope. The numbers are small; $23(13 \%)$ of 174 with breathlessness and only six $(3 \%)$ of 174 with cardiac failure in our series. Hetzel et al reported similar figures ${ }^{3}$; 21 of their 324 patients $(6.5 \%)$ were in cardiac failure at the time of pacing. Although some series have reported a higher frequency of cardiac failure of $13-19 \%,{ }^{1617}$ it is uncertain how many of these patients also had syncope. Figures from the British Pacing Group indicate that $5 \cdot 7 \%$ of patients are paced because of "heart failure", 4 but this category has not been clearly defined and the numbers with breathlessness without overt cardiac failure or syncope are unknown. They are small, perhaps reflecting a low referral rate for pacing in this group of patients. Those with syncope may be more likely to present to their doctor and their need for pacing more readily recognised.

Improvement in haemodynamic function after pacing has been demonstrated at least in some groups of patients. In the resting, unpaced state most patients with heart block have raised pulmonary artery and right heart pressures. Cardiac output is reduced despite an increased stroke volume. ${ }^{71819}$ With ventricular pacing, resting right heart pressures fall, cardiac output increases, and stroke volume falls. ${ }^{57}$ Judge et al measured the effect of different pacing rates on cardiac output. Increasing heart rate from 60 to 75 beats per minute caused a 7\% increase in cardiac output; there was little or no benefit from faster rates. ${ }^{20}$ Since cardiac output had not been measured in the unpaced state, the effect of pacing remained uncertain. Sowton found two types of rate-output curves. ${ }^{5}$ In some patients cardiac output increased steadily with pacing from the idioventricular rate to a paced rate of about 70 beats per minute; further increases in pacing rate produced no further appreciable increase in cardiac output. A second group had an optimal rate at which cardiac output was maximal, with flow falling off sharply at rates on either side of this value. Optimal rates ranged from 56 to 90 beats per minute, most occurring in the 65 to 70 beats per minute range, and produced a $52 \%$ increase in resting cardiac output. Most patients had been paced because of syncopal episodes. Benchimol et al and Bevegard et al found increases in resting cardiac output of $67 \%$ and $60 \%$ respectively. ${ }^{6}$ In contrast, Gobel et al found that pacing increased cardiac output by only $17 \%,{ }^{21}$ while Nager et al found an initial rise in cardiac output followed by a decline to prepacing levels within about 10 weeks of pacing. ${ }^{22}$ Most of the patients in these two studies were in congestive cardiac failure, however, and both groups concluded that the poor response to pacing was related to reduced left ventricular reserve.

In unpaced patients with heart block, heart rate increases little, if at all, with exercise, and cardiac output rises because of an increase in stroke volume. ${ }^{23}$ With exercise at the optimal, paced heart rate Sowton found a mean increase in cardiac output from 4 to 10 litres per minute at least for short periods; ${ }^{5}$ Benchimol et al found an average $37 \%$ rise in cardiac index on exercise, ${ }^{6}$ and some of the patients studied by Bevegard et al were able almost to double their cardiac output. ${ }^{7}$ In their patients with congestive heart failure, Gobel et al found that cardiac output rose by a modest $28 \%$ with exercise. ${ }^{21}$ 
These haemodynamic studies suggest that in most patients with heart block, pacing will cause useful increases in cardiac output both at rest and on exercise. Our results showed a significant improvement in exercise capacity after pacing in patients whose presenting symptom was breathlessness. Breathlessness was reduced, and the improvement was maintained in some patients during a follow up period of up to 30 months. In six of 13 patients exercised more than one year after pacing the improvement in exercise tolerance, as judged by walking distance, was not maintained because of increasing locomotor disability (arthritis) in five and chronic airways disease in one; nevertheless four of them were better than before they were paced. These findings are in contrast with the reported outcome in patients in cardiac failure at the time of pacing. Bernstein et al found that pacing was of little value to their patients with heart block and congestive cardiac failure, and nine out of 22 patients died from heart failure within one year of pacing. ${ }^{16}$ Hetzel et al found a symptomatic improvement after pacing in only 10 out of 21 patients with cardiac failure, and haemodynamic improvement was demonstrated in only one of six patients studied invasively. ${ }^{3}$ In contrast, none of our patients was in overt cardiac failure at the time of pacing, and this may be the explanation for the improved outcome in our group. Patients with complete heart block effectively have a fixed heart rate and are dependent upon ventricular volume reserve for increases in cardiac output. In those with severe myocardial impairment volume reserve may be insufficient even to maintain cardiac output at rest, and cardiac failure ensues. It is perhaps not surprising that in this group increasing the heart rate to 70 beats per minute causes at best the modest resting haemodynamic improvement reported by Gobel et $a^{21}$ with little or no useful increase in volume reserve, or that the short term haemodynamic benefits tend to become quickly decompensated. ${ }^{22}$ As a result pacing has little effect on exercise capacity or prognosis, which are both determined by the severity of myocardial disease. In patients with well preserved myocardial function and complete heart block, volume reserve may be used to prevent cardiac failure and to increase cardiac output on exercise. Increasing the (fixed) heart rate by pacing reduces resting end diastolic ventricular volume, ${ }^{5-7}$ leaving a greater volume reserve available for use during exercise. As a result, a larger increase in cardiac output may be achieved on exercise, and exercise capacity is increased. We believe that by selecting patients with breathlessness but no overt cardiac failure we have chosen those likely to benefit in this way from pacing.
Even among patients free from overt heart failure, however, there is likely to be a spectrum of myocardial impairment, and some patients may benefit little from pacing or even be harmed by it. We have shown that in those who benefit, an improvement is apparent 48 hours after pacing and may be confirmed objectively by a simple six minute walking test. No patient showing a substantial symptomatic improvement at $\mathbf{4 8}$ hours subsequently deteriorated. Thus if the potential long term benefit from pacing in any patient with heart block and breathlessness is in doubt, assessment by six minute walks before and during temporary cardiac pacing will provide an answer within 48 hours.

A six minute walk was chosen rather than bicycle or treadmill testing, which may frighten elderly patients and thus be an inaccurate or insensitive method of assessing their limited exercise capacity. The advantages of bicycle or treadmill testing are that it allows continuous electrocardiographic monitoring, and the use of graded exercise to limit the duration of tests in younger, fitter subjects. Neither feature was required for this study. We noted one important difference between our patients and those with chronic airways disease. In the latter group both McGavin et al and Guyatt et al showed a significant "training effect" between the first two walks and recommended two practice walks in each subject before starting any formal testing. ${ }^{824} \mathrm{We}$ found no significant training effect either in the 10 patients in heart block who were exercised twice before pacing or in the eight controls whose exercise performance remained constant on four occasions over a four week period. It may be that the fixed heart rate and limited cardiac output in our patients prevented any appreciable training effect. Thus it appears that practice walks are not an essential requirement for the assessment of patients with heart block, but two walking tests are advisable to ensure a constant exercise performance before pacing. Use of a temporary pacemaker would also allow a subsequent test with the pacemaker switched off to confirm that any apparent benefit from pacing was lost when pacing was withdrawn. It is essential that in each patient all walking tests are supervised by the same observer to eliminate variations in performance caused by differing levels of encouragement offered by different observers. ${ }^{24}$

We conclude that this simple six minute walking test can be used to identify those patients with breathlessness and heart block who will benefit from cardiac pacing. Benefit is more likely in those without overt cardiac failure, but where there is doubt a trial of temporary pacing is indicated. ${ }^{17}$ Breathlessness without syncope should not be considered a "soft" indication for cardiac pacing, which substan- 
tially increased exercise capacity in most of our patients.

We thank Dr J Russell Rees, Dr S C Jordan, and Dr $J$ Vann Jones for allowing us to study patients under their care.

\section{References}

1 Rickards AF. Where's the block? $\mathrm{Br}$ Med $\mathrm{f}$ 1984;288:737-8.

2 Guidelines for permanent pacemaker implantation, May 1984. Report of joint American College of Cardiology/American Heart Association Task Force on Assessment of Cardiovascular Procedures (Subcommittee on Pacemaker Implantation). $\mathcal{F ~} \mathrm{Am}$ Coll Cardiol 1984;4:434-42 and Circulation 1984;70: 331A-9A.

3 Hetzel MR, Ginks WR, Pickersgill AJ, Leatham A. Value of pacing in cardiac failure associated with chronic atrioventricular block. $\mathrm{Br}$ Heart $\mathcal{f}$ 1978;40:864-9.

4 British Pacing Group. Pacemaker Data Bank 1984. London: British Pacing Group.

5 Sowton E. Haemodynamic studies in patients with artificial pacemakers. Br Heart $\mathcal{F}$ 1964;26:737-46.

6 Benchimol A, Li Y-B, Diamond EG. Cardiovascular dynamics in complete heart block at various heart rates. Circulation 1964;30:542-53.

7 Bevegard S, Jonsson B, Karlof I, Langergren $H$, Sowton E. Effect of changes in ventricular rate on cardiac output and central pressures at rest and during exercise in patients with artificial pacemakers. Cardiovasc Res 1967;1:21-33.

8 McGavin CR, Gupta SP, McHardy GJR. Twelveminute walking test for assessing disability in chronic bronchitis. $\mathrm{Br}$ Med $\mathcal{F}$ 1976;i:822-3.

9 Butland RJA, Pang J, Gross ER, Woodcock AA, Geddes DM. Two-, six-, and 12-minute walking tests in respiratory disease. $\mathrm{Br}$ Med $\mathcal{F}$ 1982;284: 1607-8.

10 Gerbezius (or Verbez) M. In: Major RH, ed. Classic descriptions of disease. 3rd ed, 6th printing. Springfield, Illinois: Charles C Thomas, 1965:326-7.

11 Morgagni GB. Letter the Ninth: Which treats of epilepsy. In: Major RH, ed. Classic descriptions of disease. 3rd ed, 6th printing. Springfield, Illinois: Charles C Thomas, 1965:327-30.

12 Spens T. History of a case in which there took place a remarkable slowness of the pulse. Communicated to Dr Duncan, by Dr Thomas Spens, Physician in Edinburgh. In: Major RH, ed. Classic descriptions of disease. 3rd ed, 6th printing. Springfield, Illinois: Charles C Thomas, 1965:330-2.

13 Burnett W. Case of epilepsy, attended with remarkable slowness of the pulse. In: Major $\mathrm{RH}$, ed. Classic descriptions of disease. 3rd ed, 6th printing. Springfield, Illinois: Charles C Thomas, 1965:333-5.

14 Adams R. Cases of diseases of the heart accompanied with pathological observations. Major $\mathrm{RH}$, ed. Classic descriptions of disease. 3rd ed, 6th printing. Springfield, Illinois: Charles C Thomas, 1965:332-3.

15 Stokes W. Observations on some cases of permanently low pulse. In: Major RH, ed. Classic descriptions of disease. 3rd ed, 6th printing. Springfield, Illinois: Charles C Thomas, 1965:335-9.

16 Bernstein V, Rotem E, Peretz DI. Permanent pacemakers: 8-year follow-up study. Incidence and management of congestive failure and perforations. Ann Intern Med 1971;74:361-9.

17 Davidson DM, Braak CA, Preston TA, Judge RD. Permanent ventricular pacing: Effect on long-term survival, congestive heart failure, and subsequent myocardial infarction and stroke. Ann Intern Med 1972;77:345-51.

18 Stack MF, Rader B, Sobol BJ, Farber SJ, Eichna LW. Cardiovascular haemodynamic functions in complete heart block and the effect of isopropylnorepinephrine. Circulation 1958;17:526-36.

19 Levinson DC, Shubin H, Gunther L, Meehan JP. Hemodynamic findings in heart block with slow ventricular rates. Am f Cardiol 1959;4:440-51.

20 Judge RD, Wilson WS, Siegel JH. Hemodynamic studies in patients with implanted cardiac pacemakers. $N$ Engl f Med 1964;270:1391-5.

21 Gobel FL, Medina JR, Guenter CA, Wang Y. Immediate hemodynamic response of patients with atrioventricular block and cardiac failure to transvenous pacing. Circulation 1969;39:64-71.

22 Nager F, Buhlmann A, Schaub F. Klinische und haemodynamische befunde beim totalen AV-Block nach implantation elektrischer schrittmacher. Helv Med Acta 1966;33:240-76.

23 Johansson BW. Complete heart block: A clinical, haemodynamic and pharmacological study in patients with and without an artificial pacemaker. Acta Med Scand 1966;180 (suppl 451):7-127.

24 Guyatt GH, Pugsley SO, Sullivan MJ, et al. Effect of encouragement on walking test performance. Thorax 1984;39:818-22. 